\title{
APLICAÇÃO DE ULTRASSOM NO CONTROLE DE ASPERGILLUS FLAVUS EM COSMÉTICOS
}

\section{APPLICATION OF ULTRASOUND TO CONTROL OF ASPERGILLUS FLAVUS IN COSMETICS}

\section{Kassima Timoni Góes-Campanha ${ }^{1,3}$, Dejanira de Franceschi de Angelis ${ }^{3}$, Gerson Antonio Santarine? ${ }^{2}$, Carlos Renato Corso $^{3}$, Roberto Naves Domingos ${ }^{1,2}$}

\author{
${ }^{1}$ UNESP - Univ.Estadual Paulista, Campus de Rio Claro, Centro de Estudos \\ Ambientais, CEA, Av 24 A 1515 cep 13506900, Bela Vista, Rio Claro, São Paulo \\ Brasil. E-mail: rnaves@rc.unesp.br \\ ${ }^{2}$ UNESP - Univ.Estadual Paulista, Campus de Rio Claro, Instituto de Geociências e \\ Ciências Exatas, IGCE, Departamento de Física, Av 24 A 1515 cep 13506900, Bela \\ Vista, Rio Claro, São Paulo Brasil \\ ${ }^{3}$ UNESP - Univ.Estadual Paulista, Campus de Rio Claro, Instituto de Biociências, IB, \\ Departamento de Bioquímica e Microbiologia, Av 24 A 1515 cep 13506900, Bela \\ Vista, Rio Claro, São Paulo Brasil
}

\section{RESUMO}

Devido ao alto poder de contaminação dos cosméticos por fungos, é de grande importância o desenvolvimento de novas técnicas para preservação desses, uma vez que a contaminação microbiológica pode, além de causar a deterioração do produto, apresentar danos à saúde do consumidor. Procurou-se, então, nesse trabalho, determinar a eficácia do ultrassom na diminuição do crescimento do fungo Aspergillus flavus em cosméticos. Para isso, amostras de cosméticos contaminados com o fungo foram irradiadas em equipamento gerador de ultrassom modelo VCX600, nos tempos 0 (controle), 12 minutos, 16 minutos e 20 minutos, com a mesma intensidade (600 Watts $\left./ \mathrm{cm}^{2}\right)$ e temperatura constante $\left(25^{\circ} \mathrm{C}\right)$. Mostrou-se que o uso do ultrassom é eficiente na inibição do crescimento do microrganismo e, consequentemente, na preservação dos cosméticos, comprovando ser o ultrassom um excelente agente biocida na preparação e preservação de produtos cosméticos emulsionáveis. Uma diminuição significativa foi constatada após 20 minutos de irradiação, com o aparelho operando de modo contínuo.

Palavras-chave: Aspergillus flavus. Cosméticos. Ultrassom. Contaminação. Cavitação.

\begin{abstract}
The effect of ultrasound on organic compounds in living tissue and are often related to the cavitation' phenomenon, a term used to describe the formation of cavities or bubbles in a liquid medium containing varying amounts of gas or vapor that are dissolved in the middle. In medicine it
\end{abstract}


is suggested that ultrasound of high intensity is able to cause some reduction in certain infectious agents and microbiology, mechanisms of inactivation of cells appear to be associated with cavitation. Due to the high power of fungal contamination of cosmetics, it is important to develop new techniques to preserve it to rapid fungi deterioration and subsequent consumer health hazard. On the present work it was probed the efficiency of ultrasound in decreasing the growth of Aspergillus flavus in cosmetic. Thus contaminated samples with the above mentioned fungus, were irradiated at constant temperature $\left(25^{\circ} \mathrm{C}\right)$ and power $\left(600 \mathrm{~W} / \mathrm{cm}^{2}\right)$, for a variety of time exposure: 0 (control), 12, 16, and 20 minutes. The ultrasound generator model VCX- 600 was utilized.It was possible to show that the use of ultrasound is efficient in decreasing the growth of microrganisms and thus preserve cosmetic which went from $35,000 \mathrm{CFU} / \mathrm{mL}$ to $50 \mathrm{CFU} / \mathrm{mL}$. Ultrasound is a excellent biocide agent in preparation and preservation of emulsion-type cosmetics. Twenty minutes of continuous irradiation yelded an almost complete depletion of microrganisms.

Keywords: Aspergillus flavus. Cosmetics. Ultrasound. Contamination. Cavitation.

\section{INTRODUÇÃO}

A cavitação e a microcorrenteza acústica são fenômenos físicos importantes a considerar. Cavitação é a formação de bolhas devido à compressão e descompressão muito rápida de gases dissolvidos no meio biológico. É um fenômeno predominante na utilização da irradiação por ultrasom no modo contínuo. Ao implodir, as bolhas liberam energia suficiente para destruir microrganismo, células vegetais. Essas implosões são acompanhadas de variações de temperatura de $10^{4} \mathrm{~K}$ e pressões de $10^{3}$ atm e uma transferência de calor associada a uma taxa de variação de temperatura de $10^{10} \mathrm{~K} \mathrm{~S}^{-1}$.

A cavitação é significativa quando se utiliza ultra-som no modo contínuo, e importante neste trabalho por homegeneizar e emulsificar a mistura e esterilizar o produto final.

Comercialmente, a produção, utilizando esta técnica, tem a disposição no mercado reatores com capacidade de vinte toneladas/hora. Os dispositivos podem ser adequados tanto para produzir cavitação ou microcorrenteza acústica.

\section{MATERIAL E MÉTODO}

a) Microrganismo

Aspergillus flavus, isolado de material cosmético que apresentou-se contaminado.

b) Meio de cultura para preservação do microrganismo e esporulação

Agar Saboraud 2\% (DIFICO Manual; 1984)

c) Cosmético

Base cosmética: tipo óleo - água (loção Lanette)

$\mathrm{c}_{1}$ ) Cera autoemulsionante $(\text { Lanette } \mathrm{N})^{\mathrm{R}} \quad 2 \%$ Água destilada qsp $100 \%$

$\mathrm{c}_{2}$ ) Cera autoemulsionante $(\text { Lanette } \mathrm{N})^{\mathrm{R}} \quad 2 \%$ Suspensão de esporos qsp $\quad 60 \mathrm{~mL}$ 
d) Gerador de ultrassom sonda.

Processador Sonics VC*600 Sonics Inc, $20 \mathrm{KH}_{\mathrm{z}}, 600 \mathrm{~W}$ (modo contínuo), Guia de ondas tipo

e) Esporos do Fungo Contaminante

$10^{6}$ esporos $/ \mathrm{mL}$

As amostras foram preparadas obedecendo metodologia específica de manipulação de emulsões, onde o aquecimento foi substituído pela irradiação ultra-sônica. A irradiação foi processada num reator de vidro PIREX $^{\mathrm{R}}$, mantido a temperatura constante em um banho de gelo, para que fosse avaliado somente o efeito da cavitação.

Irradiação das amostras não contaminadas e contaminadas.

$\mathrm{T}_{0}=1 \mathrm{~min} ; \mathrm{T}_{4}=4 \mathrm{~min} ; \mathrm{T}_{12}=12 \mathrm{~min} ; \mathrm{T}_{16}=16 \min \mathrm{e} \mathrm{T}_{20}=20 \mathrm{~min}$

Irradiações foram processadas a intensidades constantes a $50 \mathrm{~W} / \mathrm{cm}^{2}$

Para cada tempo de irradiação, os ensaios foram realizados em triplicata.

\section{RESULTADOS E DISCUSSÃO}

As Tabelas 1 e 2 apresentam resultados da influência do tempo de irradiação na suspensão de esporos de Aspergillus flavus, onde observa-se uma redução de $30 \%$ comparado com a concentração inicial e diminuição da concentração. Na Figura 1 os gráficos correspondem a essas reduções.

Tabela 1. Tempo de irradiação ultrasônica dos esporos de Aspergillus flavus, com base em unidades formadoras de colônias por ml (UFC.ML $\left.{ }^{-1}\right)$

\begin{tabular}{|c|c|}
\hline Tempo (minutos) & UFC.MI $^{-1}$ \\
\hline $1\left(\mathrm{~T}_{0}\right)$ & $3.5510^{5}$ \\
\hline 4 & $3.1510^{5}$ \\
\hline 8 & $3.1010^{5}$ \\
\hline 12 & $3.0510^{5}$ \\
\hline 16 & $2.9510^{5}$ \\
\hline 20 & $2.5010^{5}$ \\
\hline
\end{tabular}

Os resultados mostram que houve uma redução em UFC de $30 \%$ com base no tempo inicial. 
Tabela 2. Valor médio das unidades formadoras de colônias a diferentes concentrações iniciais em função do tempo de irradiação das amostras por ultrassom

\begin{tabular}{|c|c|c|c|c|}
\hline Ensaio & $\mathbf{T}_{\mathbf{0}}(\mathbf{1} \mathbf{m i n})$ & $\left.\mathbf{T}_{\mathbf{1 2}} \mathbf{( 1 2} \mathbf{~ m i n}\right)$ & $\left.\mathbf{T}_{\mathbf{1 6}} \mathbf{( 1 6 m i n}\right)$ & $\mathbf{T}_{\mathbf{2 0}}(\mathbf{2 0} \mathbf{~ m i n})$ \\
\hline 1 & 135000 & 16000 & 7200 & 400 \\
\hline 2 & 80000 & 10000 & 5000 & 200 \\
\hline 3 & 60000 & 8000 & 1500 & 100 \\
\hline 4 & 35000 & 1300 & 300 & 50 \\
\hline
\end{tabular}

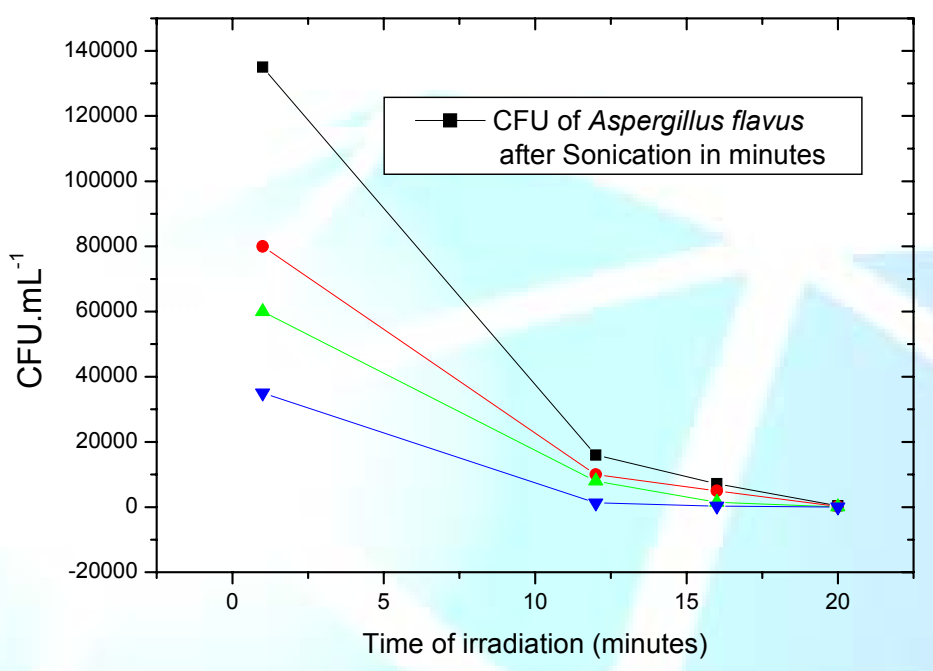

Figura 1. UFC em função do tempo de sonicação

\section{CONCLUSÃO}

O tratamento do cosmético contaminado com o fungo Aspergillus flavus (teste desafio) com ondas ultra-sônicas mostrou-se eficiente levando-se em consideração a diminuição do número de microrganismos presentes após irradiação.

Observou-se que, através do uso do ultrassom para irradiação do cosmético, obteve-se o controle de microrganismos presentes no produto.

Os resultados obtidos mostram uma boa qualidade do produto final, ressaltando que o ultrassom, na forma aqui utilizado é um excelente agente biocida na preparação e preservação de produtos cosméticos emulsionáveis.

A não utilização de biocidas possibilita a utilização do produto por pessoas alérgicas a esses componentes na fórmula.

\section{BIBLIOGRAFIA}

Conselier, J.R.; Delmas, H.; Wilhelm, A.M.; Abismail, B. Ultrasound emulsification. Journal of Dispersion Science and Technology, 23 (1-3), 333-349, 2002.

DIFCO MANUAL, Tenth Edition, Difco Laboratories. Detroit, Michigan, USA 1984. 